\title{
Simultaneous mode A and mode B echobiometry of senile cataractous eyes in dogs
}

[Ecobiometria simultânea em modos A e B de olhos acometidos por catarata senil, em cães]

\author{
B.C. Martins ${ }^{1}$, F.S. Lima $^{2}$, J.L. Laus ${ }^{1}$ \\ ${ }^{1}$ Faculdade de Ciências Agrárias e Veterinárias - UNESP \\ Via de Acesso Prof. Paulo Donato Castellane, s/n \\ 14884-900 - Jaboticabal, SP \\ ${ }^{2}$ Aluno de pós-graduação - University of Florida - Gainesville, USA
}

\begin{abstract}
The evaluation of lens by ultrasonography, previously to phacoemulsification, can offer relevant information, markedly such as aspects and dimensions, allowing design safer surgical strategies with enhanced outcomes. Within the contents of this research, the biometry was performed in lens of dogs with senile immature, mature, and diabetic cataracts, previously to phacoemulsification, using mode A and mode B ultrasonography, simultaneously. The values obtained for axial diameter of the eyes, anterior chamber, lens, and vitreous chamber were, respectively, $19.22 \mathrm{~mm}, 2.35 \mathrm{~mm}, 7.94 \mathrm{~mm}$, and $8.94 \mathrm{~mm}$. Diabetic cataractous lens were larger $(8.90 \mathrm{~mm})$, compared to mature cataract $(8.12 \mathrm{~mm})$. Lens with immature cataract were smaller in dimension than those with mature and diabetic cataracts.
\end{abstract}

Keywords: dog, echobiometry, cataract

\section{RESUMO}

A avaliação da lente pela ultrassonografia, previamente à facoemulsificação, pode fornecer informações relevantes, notadamente, quanto ao seu aspecto e dimensões, que permitem delinear estratégias cirúrgicas mais seguras e com melhores resultados. Nesta pesquisa, realizou-se a biometria da lente de cães acometidos por catarata senil imatura, madura ou diabética, previamente à facoemulsificação, valendo-se da ultrassonografia em modo A e B, simultaneamente. Os valores obtidos para o diâmetro axial do bulbo do olho, câmara anterior, lente e câmara vítrea foram, respectivamente, 19,22mm, 2,35mm, 7,94mm e 8,94mm. Lentes cataratogênicas pertencentes a animais diabéticos apresentaram dimensões maiores $(8,90 \mathrm{~mm})$, comparativamente àquelas que apresentavam catarata madura $(8,12 \mathrm{~mm})$. Lentes acometidas por catarata imatura apresentaram menor dimensão (7,06mm), comparativamente às demais.

Palavras-chave: cão, ecobiometria, catarata

\section{INTRODUCTION}

The accurate evaluation of the lens, previous to its removal, is an obligatory condition towards to satisfactory surgical results. Despite the enormous quantity of data regarding the posterior chamber alteration of cataractous eyes, there are very few studies referring to biometry of the cataractous lens in dogs (Slatter, 2001; Salman et al., 2006).

Recebido em 15 de setembro de 2008

Aceito em 1 de dezembro de 2009

* Autor para correspondência (corresponding author)

E-mail: jllaus@fcav.unesp.br
Osmotic events can occur during the cataract development, mainly in those cases when diabetes is present, leading to the accumulation of water into the lens, increasing its thickness. It is speculated that the increase in the size of the lens can contribute to the post-surgical glaucoma development, due to the narrowing of the iridocorneal angle (Brazitikos et al., 1999; Williams, 2004). So, the lens diameter is an important tool to select patients previously to the phacoemulsification (Brazitikos et al., 2003). 
The use of ultrasonography to measure the axial diameter of the dog has been reported by some authors (Schiffer et al., 1982; Cottrill et al., 1989). However, the first study about the biometry of normal lens and cataractous lens in dogs was conducted by Williams (2004) using only mode B ultrasonography. Results showed that lens of dogs with diabetic cataracts were thicker than lens of dogs without it. In addition, that those dogs had smaller depth of anterior chamber.

Despite the mode B echography be used for biometry, the presence of some conditions, such as cataracts and hyphema, can difficult the measurements for limiting the visualization of the intraocular echoic spikes, mainly the posterior capsule one. Therefore, recent studies recommend the mode $\mathrm{A}$ and mode $\mathrm{B}$ association to measure intraocular structures.

The objectives of this study were to evaluate the length of the eye, anterior chamber, lens, and vitreous of dogs with immature, mature, and diabetic senile cataract, using mode A and mode B ultrasonography, simultaneously.

\section{MATERIALS AND METHODS}

The project was submitted to and approved by the Committee of Ethics and Animal Welfare at the Faculdade de Ciências Agrárias e Veterinárias - UNESP - Jaboticabal, SP (Protocol 007105-06). Bioethics cares follow the guidelines established by the Association for Research in Vision and Ophthalmology - ARVO (NHI..., 1985).

Fifteen male and female dogs, aging from eight to 14-year-old, affected with different stages of senile cataracts were used. The dogs were clinically and ophthalmologic evaluated using pupillary light reflex, Schirmer tear test, slitlamp biomicroscopy, tonometry, gonioscopy, fluorescein staining, indirect binocular ophthalmoscopy, and eletroretinography.

For the ultrasonography examination, a $10 \mathrm{MHz}$ probe ophthalmic ultrasound equipment was used with mode A and mode (Ultrascan A/B - Alcon). Images were printed using video-printer with thermo-sensible paper.
Topic corneal anesthesia with proximetacaine chloride in direct instillation on the ocular surface (Dziezyc et al., 1987; Hager et al., 1987), manual restraint, and sternal recumbency (Hager et al., 1987) were performed as previous procedures. The blepharostasis was manually induced. Sterile gel was used as contact and conduction between the probe and the examined eye (Dziezyc et al., 1987; Hager et al., 1987).

The immersion technique was performed for biometric examination. Mode A and mode B echography were simultaneously, made to enhance the visualization of structures as well the corneal, anterior capsule, posterior capsule, and retina spikes. Corneal technique was carried out with the probe placed at axial cornea. The eye axial length, anterior chamber length, lens length, and vitreous length were measured.

After the procedure, all eyes were cleaned with $0.9 \%$ sodium chloride solution and evaluated for possible iatrogenic lesions.

\section{RESULTS AND DISCUSSION}

Twenty eyes of 15 dogs were assessed, since two dogs had unilateral cataract. The values obtained for biometry are reported in Table 1 .

Diabetes mellitus was diagnosed in three animals (numbers 5, 7, and 15). Those animals were previously treated at the time of ophthalmic examination.

At the ophthalmic evaluation, mature cataract was observed in 23 eyes ( $82.4 \%$ of the cases). In these cases, adequate evaluation of the nucleus, posterior cortex, and posterior capsule of lens was not possible. Immature cataract was identified in five eyes $(21.8 \%)$.

In these eyes, the axial area of the posterior cortex was compromised and in some cases the axial area of the nucleus and posterior area of the cortex were also affected. Hypermature, incipient, and morganian cataracts were not observed. Posterior capsular cataracts could not be diagnosed, due to the lens opacity. 
Table 1. Echobiometry values ( $\mathrm{AL}=$ axial lenght, $\mathrm{AC}=$ anterior chamber, $\mathrm{L}=$ lens, $\mathrm{V}=$ vitreous) from right (D) and left (S) eyes of dogs with senile cataracts

\begin{tabular}{cccccccc}
\hline Animal & Eye & Cataract & Diabetes & AL $(\mathrm{mm})$ & AC $(\mathrm{mm})$ & L $(\mathrm{mm})$ & V $(\mathrm{mm})$ \\
1 & D & mature & No & 19.57 & 3.27 & 7.18 & 9.12 \\
1 & S & mature & No & 19.35 & 2.26 & 7.43 & 9.66 \\
2 & D & mature & No & 20.51 & 2.73 & 9.60 & 8.18 \\
2 & S & mature & No & 19.56 & 2.49 & 10.52 & 6.55 \\
3 & S & imatura & No & 18.03 & 1.56 & 7.43 & 9.04 \\
4 & D & imatura & No & 18.54 & 2.26 & 5.84 & 10.44 \\
4 & S & mature & No & 19.39 & 2.34 & 6.84 & 10.21 \\
5 & S & mature & Yes & 17.72 & 2.34 & 7.51 & 7.87 \\
6 & D & imatura & No & 20.27 & 3.12 & 7.18 & 9.97 \\
6 & S & mature & No & 20.06 & 2.88 & 6.34 & 10.83 \\
7 & D & mature & Yes & 19.81 & 1.87 & 10.77 & 7.17 \\
7 & S & mature & Yes & 20.03 & 2.03 & 10.68 & 7.32 \\
8 & D & mature & No & 19.38 & 0.70 & 10.18 & 8.49 \\
8 & S & imatura & No & 19.50 & 2.10 & 7.26 & 10.13 \\
9 & D & mature & No & 19.74 & 3.12 & 7.43 & 9.19 \\
9 & S & mature & No & 19.04 & 2.03 & 7.43 & 9.58 \\
10 & D & mature & No & 20.90 & 2.88 & 8.51 & 9.51 \\
10 & S & mature & No & 20.52 & 2.73 & 7.43 & 10.36 \\
11 & D & mature & No & 19.00 & 1.17 & 9.18 & 8.65 \\
11 & S & mature & No & 19.49 & 2.42 & 8.35 & 8.73 \\
12 & D & mature & No & 21.01 & 2.55 & 10.83 & 7.58 \\
12 & S & mature & No & 19.56 & 3.12 & 7.01 & 9.43 \\
13 & D & mature & No & 17.48 & 1.87 & 7.43 & 8.18 \\
13 & S & imatura & No & 17.10 & 1.40 & 7.60 & 8.10 \\
14 & D & mature & No & 17.99 & 2.88 & 6.84 & 8.26 \\
14 & S & mature & No & 17.74 & 2.73 & 6.68 & 8.34 \\
15 & D & mature & Yes & 18.72 & 2.73 & 6.09 & 9.90 \\
15 & S & mature & Yes & 18.29 & 2.18 & 6.68 & 9.43 \\
\hline
\end{tabular}

The adequate identification of the intraocular spikes using the ultrasound is extremely important to the accurate measurement of the intraocular structures. In this study, mode A and mode B echography were performed as proposed by Boroffka et al. (2006). In all cases, the identification of the spikes related to cornea, anterior and posterior lens capsule, and retina were appropriate.

The echobiometry was performed using only manual restraint and mechanic blepharostasis. The axial length of the eyes ranged from $17.10 \mathrm{~mm}$ to $21.01 \mathrm{~mm}$ (mean \pm SD: $19.22 \pm 1.05 \mathrm{~mm}$ ). It was observed a difference between the eyes axial length in just one dog $(6.7 \%)$. It was a non-diabetic dog in which the right eyes showed increased lens volume.

The anterior chamber length ranged from $0.70 \mathrm{~mm}$ to $3.27 \mathrm{~mm}$ (mean $\pm \mathrm{SD}: 2.35 \pm 0.7 \mathrm{~mm}$ ). One of the animals had a considerable smaller anterior chamber at the right eye $(0.7 \mathrm{~mm})$ due to lens anterior luxation (Fig. 1).

The lengths obtained for the lens ranged from $5.84 \mathrm{~mm}$ to $10.83 \mathrm{~mm}$ (mean \pm SD: $7.94 \mathrm{~mm} \pm 1.5 \mathrm{~mm}$ ). Seven eyes had lens varying from $5.00 \mathrm{~mm}$ to $7.00 \mathrm{~mm}(25 \%)$. Fourteen lenses ranged from $7.01 \mathrm{~mm}$ to $9.00 \mathrm{~mm}$ (50\%) (Fig. 2) and seven eyes showed lens ranging from $9.01 \mathrm{~mm}$ to $11.00 \mathrm{~mm}$. In the first group, two of the lenses were from a diabetic dog. In the second group, only one lens presented diabetic cataract. In the third group, similarly to the first group, two lenses belonged to one same diabetic dog (number 7) (Fig. 3). The mean value of lenses of animals with immature cataract was $7.06 \mathrm{~mm} \pm 0.7 \mathrm{~mm}$. Mature cataract had mean values of $8.12 \mathrm{~mm} \pm 1.5 \mathrm{~mm}$. In addition, diabetic dogs had mean values of $8.91 \mathrm{~mm} \pm 2.1 \mathrm{~mm}$. There was no case of decreased lens length. 


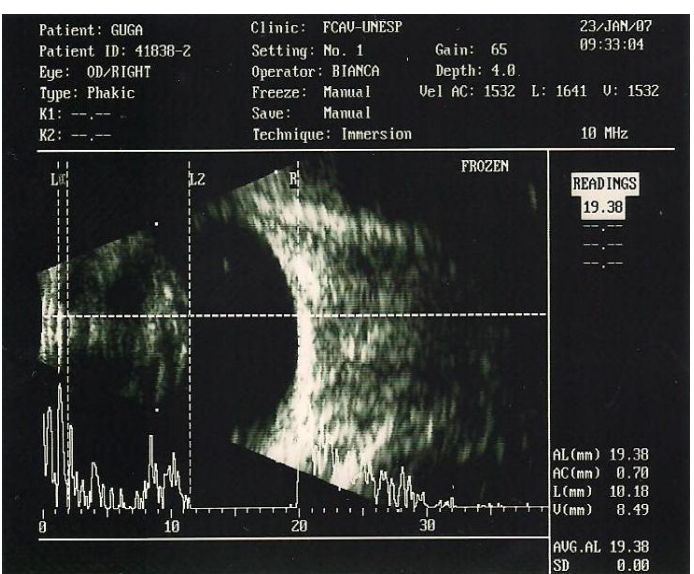

Figure 1. Ultrasonographic image of right eye of a dog with cataracts and anterior lens luxation. Note smaller anterior chamber $(0.70 \mathrm{~mm})$.

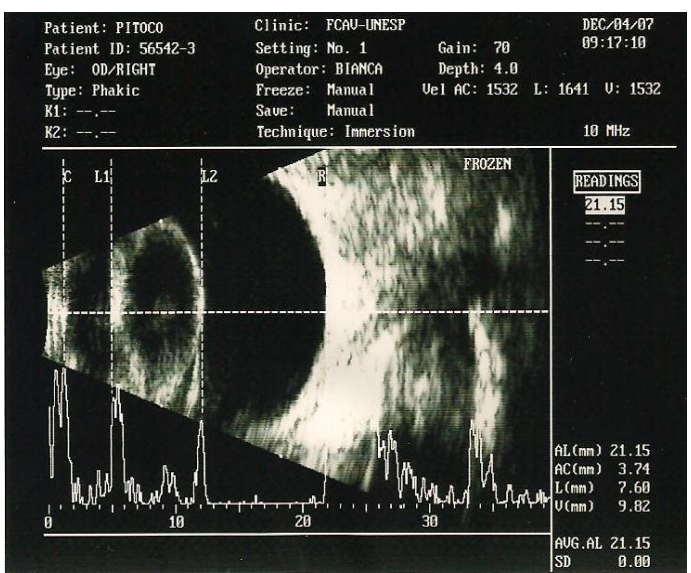

Figure 2. Ultrasonographic image of right eye of a dog with immature cataracts. Lens diameter is $7.6 \mathrm{~mm}$.

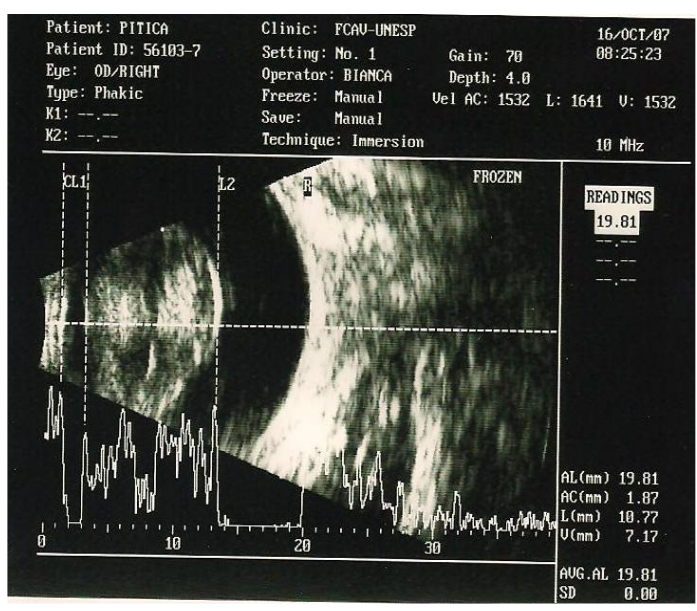

Figure 3. Ultrasonographic image of right eye of a dog with diabetic cataracts. Note higher lens diameter $(10.77 \mathrm{~mm})$.
The first study regarding echobiometry of cataractous lens in dogs was conducted by Williams (2004), using mode B ultrasonography. Williams reported $6.4 \mathrm{~mm}, 7.4 \mathrm{~mm}$, and $8.4 \mathrm{~mm}$, respectively for lenses of immature, mature, and diabetic cataract. In this study, lenses of immature cataract, mature, and diabetic cataract were respectively, $7.06 \pm 0.7 \mathrm{~mm}, 8.12 \pm 1.6 \mathrm{~mm}$, and $8.9 \pm 2.1 \mathrm{~mm}$.

The mode B ultrasonography was also used to verify the eyes axial length, anterior chamber length, and lens length of normal Beagles (Boroffka et al., 2006). The values were respectively, $20.9 \mathrm{~mm}, 4.0 \mathrm{~mm}$, and $7.9 \mathrm{~mm}$. The same measurements for this present study were, respectively, $19.2 \mathrm{~mm}, 2.35 \mathrm{~mm}$, and $7.9 \mathrm{~mm}$, which were smaller compared to the previous study. However, it is important to clarify that the conditions of the lenses were different.

The values obtained for the vitreous ranged from $6.55 \mathrm{~mm}$ to $10.83 \mathrm{~mm}$ (mean $\pm \mathrm{SD}: 8.94 \pm 1.09 \mathrm{~mm}$ ). Alteration of this structure size was not observed.

\section{CONCLUSIONS}

Dog lenses affected with diabetic cataract had increased diameter, compared to those with mature cataract. Mature cataract had higher dimensions compared to immature cataracts. The use of mode A and mode B ultrasonography, simultaneously, is helpful for determining the echoic spikes for the biometric evaluation of cataractous lens.

\section{ACKNOWLEDGMENT}

The authors would like to thank CAPES and FAPESP for the scholarship and the financial support.

\section{REFERENCES}

BOROFFKA, A.E.B.; VOORHOUT, G.; VERBRUGGEN, A.M. et al. Intraobserver and interobserver repeatability of ocular biometric measurements obtained by means of B-mode ultrasonography in dogs. Am. J. Vet. Res., v.67, p.1743-1749, 2006.

BRAZITIKOS, P.D.; ANDRODI, S.; PAPADOPOULOS, N.T. et al. A-scan quantitative echography of senile cataracts and correlation with phacoemulsification parameters. Curr. Eye Res., v.27, p.175-181, 2003. 
BRAZITIKOS, P.D.; TSINOPOULOS, I.T.; PAPADOPOULOS, N.T. et al. Ultrasonographic classification and phacoemulsification of white senile cataracts. Ophthalmology, v.106, p.21782173, 1999.

COTTRILL, N.B.; BANKS, W.J.; PECHMAN, R.D. Ultrasonic and biometric evaluation of the eye and the orbit of dogs. Am. J. Vet. Res., v.50, p.898, 1989.

DZIEZYC, J.; HAGER, D.A.; MILLCHAMP, N.J. Two-dimensional real-time ocular ultrasonography in the diagnosis of ocular lesions in dogs. J. Am. Anim. Hosp. Assoc., v.23, p.501-8, 1987.

HAGER, D.A.; DZIEZYC, J.; MILLCHAMP, N.J. Two dimensional real-time ocular ultrasonography in the dog: technique and normal anatomy. Vet. Radiol., v.28, p.60-65, 1987.
$\mathrm{NIH}$ guide for the care and use of laboratory animals. Bethesda, MD: National Institutes of Health, 1985. (NIH Publication, 85-23).

SALMAN, A.; PARMAR, P.; VANILA, C.G. et al. Is ultrasound essential before surgery in eyes with advanced cataracts? J. Postgrad. Med., v.52, p.19-22, 2006.

SCHIFFER, S.P.; RANTANEM, N.W.; LEARY, G.A. et al. Biometric study of the canine eye, using A-mode ultrasonography. Am. J. Vet. Res., v.43, p.23-26, 1982.

SLATTER, D. Lens. In:

Fundamentals of veterinary ophthalmology. 3.ed. Philadelphia: W.B. Saunders, 2001. p.381-410,

WILLIAMS, D.L. Lens morphometry determined by B-mode ultrasonography of the normal and cataractous canine lens. Vet. Ophthalmol., v.7, p.91-95, 2004. 